University of Wollongong

Research Online

Faculty of Engineering and Information

Faculty of Engineering and Information

Sciences - Papers: Part A

Sciences

$1-1-2016$

\title{
The impact of electronic health records on risk management of information systems in Australian residential aged care homes
}

Tao Jiang

University of Wollongong, tj290@uowmail.edu.au

Ping Yu

University of Wollongong, ping@uow.edu.au

David M. Hailey

University of Wollongong, dhailey@uow.edu.au

Jun Ma

University of Wollongong, jma@uow.edu.au

Jie Yang

University of Wollongong, jiey@uow.edu.au

Follow this and additional works at: https://ro.uow.edu.au/eispapers

Part of the Engineering Commons, and the Science and Technology Studies Commons

Research Online is the open access institutional repository for the University of Wollongong. For further information contact the UOW Library: research-pubs@uow.edu.au 


\title{
The impact of electronic health records on risk management of information systems in Australian residential aged care homes
}

\begin{abstract}
To obtain indications of the influence of electronic health records (EHR) in managing risks and meeting information system accreditation standard in Australian residential aged care (RAC) homes. The hypothesis to be tested is that the RAC homes using EHR have better performance in meeting information system standards in aged care accreditation than their counterparts only using paper records for information management. Content analysis of aged care accreditation reports from the Aged Care Standards and Accreditation Agency produced between April 2011 and December 2013. Items identified included types of information systems, compliance with accreditation standards, and indicators of failure to meet an expected outcome for information systems. The Chi-square test was used to identify difference between the RAC homes that used EHR systems and those that used paper records in not meeting aged care accreditation standards. 1,031 (37.4\%) of 2,754 RAC homes had adopted EHR systems. Although the proportion of homes that met all accreditation standards was significantly higher for those with EHR than for homes with paper records, only 13 RAC homes did not meet one or more expected outcomes. 12 used paper records and nine of these failed the expected outcome for information systems. The overall contribution of EHR to meeting aged care accreditation standard in Australia was very small. Risk indicators for not meeting information system standard were no access to accurate and appropriate information, failure in monitoring mechanisms, not reporting clinical incidents, insufficient recording of residents' clinical changes, not providing accurate care plans, and communication processes failure. The study has provided indications that use of EHR provides small, yet significant advantages for RAC homes in Australia in managing risks for information management and in meeting accreditation requirements. The implication of the study for introducing technology innovation in RAC in Australia is discussed.
\end{abstract}

\section{Keywords}

impact, electronic, health, records, risk, management, information, systems, australian, residential, aged, care, homes

\author{
Disciplines \\ Engineering I Science and Technology Studies
}

\section{Publication Details}

Jiang, T., Yu, P., Hailey, D., Ma, J. \& Yang, J. (2016). The impact of electronic health records on risk management of information systems in Australian residential aged care homes. Journal of Medical Systems, 40 (9), 204-1-204-7. 
ARTICLE TITLE: The Impact of Electronic Health Records on Risk Management of Information Systems in Australian Residential Aged Care Homes

Authors' full names and degrees:

Tao Jiang, Master of Public Health, Master of Health Informatics

School of Computing and Information Technology, University of Wollongong, Wollongong, 2522, NSW, Australia

Ping Yu, PhD.

School of Computing and Information Technology, University of Wollongong, Wollongong, 2522, NSW, Australia

David Hailey, PhD.

School of Computing and Information Technology, University of Wollongong, Wollongong, 2522, NSW, Australia

Jun Ma, PhD.

SMART Infrastructure Facility, University of Wollongong, Wollongong, 2522, NSW, Australia

Jie Yang, $\mathrm{PhD}$.

SMART Infrastructure Facility, University of Wollongong, Wollongong, 2522, NSW, Australia

Authors' affiliation(s):

Corresponding author full contact details:

Name: Ping Yu

Address: School of Computing and Information Technology, University of Wollongong.

Postcode: 2522

State: NSW

City: Wollongong

Country: Australia

Tel: +61242215412

Fax: +61 242214045

Email: ping@uow.edu.au

Keywords relevant to the content of your manuscript:

Information technology

Risk management

Standards of care

Word count: 2590 words 


\section{ABSTRACT}

Objective(s): To obtain indications of the influence of electronic health records (EHR) in managing risks and meeting information system accreditation standard in Australian residential aged care (RAC) homes. The hypothesis to be tested is that the RAC homes using EHR have better performance in meeting information system standards in aged care accreditation than their counterparts only using paper records for information management.

Method: Content analysis of aged care accreditation reports from the Aged Care Standards and Accreditation Agency produced between April 2011 and December 2013. Items identified included types of information systems, compliance with accreditation standards, and indicators of failure to meet an expected outcome for information systems. The Chi-square test was used to identify difference between the RAC homes that used EHR systems and those that used paper records in not meeting aged care accreditation standards.

Results: 1,031 (37.4\%) of 2,754 RAC homes had adopted EHR systems. The proportion of homes that met all accreditation standards was significantly higher for those with EHR than for homes with paper records. Of $13 \mathrm{RAC}$ homes that did not meet one or more expected outcomes, 12 used paper records and nine of these failed the expected outcome for information systems. Risk indicators for not meeting information system standard were no access to accurate and appropriate information, failure in monitoring mechanisms, not reporting clinical incidents, insufficient recording of residents' clinical changes, not providing accurate care plans, and communication processes failure.

Conclusion: The study has provided indications that use of EHR provides small, yet significant advantages for RAC homes in Australia in managing risks for information management and in 
meeting accreditation requirements.

KEYWORDS: Electronic health records, information system, residential aged care, nursing home, long-term care, accreditation, nursing documentation, risk management. 


\section{INTRODUCTION}

Despite the potential of electronic health records (EHR) to significantly improve the quality of information management in comparison with paper-based records [1-3], there are limited reports of the actual benefits of EHR for information management in residential aged care. In a qualitative research study with focus-group data collection, Cherry et al. found that the managers in long-term care homes with EHR usage experience perceived these systems to be more efficient than paper records, giving improved quality and accuracy of documentation. They provide easier access to charts and resident care information [1]. They also improve management ability to monitor resident care activities and initiate improvement actions, and better resident outcomes related to improved documentation quality.

Based on a publication of the US Institute of Medicine, we define aged care EHR in this study as a repository of aged care service recipients' data in digital form [2]. Aged care EHR contains retrospective, concurrent, and prospective longitudinal electronic health and aged care service information pertaining to a care recipient. They are accessible by multiple authorized users. EHR are generated and maintained by aged care service providers with the primary purpose of giving continuing, efficient and safe health and aged care for their clients $[4,5]$. The functionality of EHR may include demographic information, admission assessment, care planning, ongoing assessment, nursing charts, progress and incident reporting care planning, medication management, ongoing assessment, nursing charts, progress and incident reporting [6].

Residential aged care (RAC) homes in Australia are similar to long-term care (LTC) homes in the USA. They are facilities that offer 24-hour nursing supervision and a range of medical, nursing, 
personal and social services to meet the needs of chronically ill or disabled individuals.

Increasing number of RAC homes in Australia and the United States have been introducing EHR systems over the last decade. The reasons are to standardise the structure and process of client record keeping, and improve the quality and efficiency of information management. These changes are expected to increase the quality adjusted life years of the older people and improve health decision-making, and access to patients' medical history., EHR systems should also provide better evidence that care services meet nursing and accreditation standards and legal requirements [7-12].

After using EHR systems for up to two years, care staff in nine Australian RAC homes perceived the benefits of EHR to them include quick data entry and retrieval, improved format and content of records, facilitating internal and external communication, and better understanding of residents' requirements [5]. Unintended adverse consequences included difficulties for some staff in data entry and information retrieval, resistance to using the system, increased complexity of information management, and end user concerns about access. Reasons included the nature of the EHR systems and the ways the systems were implemented and used by nursing staff [13].

A nursing documentation audit in seven Australian RAC homes provided information on key differences between the electronic and paper record formats $[7,8]$. Nursing care plans in the EHR system documented more signs and symptoms of resident problems and evaluation of care than the paper-based plans, but had a lower mean quality score. The EHR plans contained fewer problem or diagnosis statements, contributing factors and resident outcomes than the paper-based system. Both types of nursing care plan were weak in documenting measurable and concrete 
resident outcomes. The overall quality of documentation content for the nursing process was no better in the electronic system than in the paper-based system.

However, despite the potential of EHR to significantly improve the quality of information management in comparison with paper-based records $[10,14,15]$, there are limited reports of the actual benefits of EHR in RAC. Therefore, the aim of this study was to identify any differences in meeting aged care accreditation requirements between the RAC homes that used EHR for information management and those that used paper records. The hypothesis to be tested is that the RAC homes using EHR have better performance in meeting information system standards in aged care accreditation than those that use paper records for information management. This analysis will help us understand the contribution of EHR in managing risks for information management in Australian residential aged care (RAC) homes.

\section{Aged Care Accreditation in Australia}

The Australian government implements a comprehensive accreditation system through the Australian Aged Care Quality Agency (AACQA), which determines whether the aged care services provided by an RAC home meet the relevant safety standards. AACQA commenced operation in 2014, superseding the Aged Care Standards and Accreditation Agency (ACSAA).

The accreditation process in Australia involves self-assessment by RAC homes against the accreditation standards and the submission of an application for accreditation. This is followed by a desk audit and a site audit by a team of registered aged care quality assessors. A person is only qualified as a registered aged care quality assessor after completing approved training and orientation of aged care accreditation [16]. When auditing an RAC home, the assessors are required to observe the Code of Conduct and to have no pecuniary or other interest that may 
conflict with a proper audit [16]. Given the high standards of performance and integrity required in aged care accreditation, the report produced by the assessors after a site visit is treated as valid and reliable official report of the AACQA. A decision about the home's accreditation, either meeting or not meeting the standards, is then made by AACQA based on the self-assessment by the RAC home, desk audit and site audit. Finally, an accreditation certificate is issued, as well as the accreditation report.

According to the Australian Aged Care Act [17], RAC homes are required to meet the accreditation standards at all times and ensure the safe care of residents. When a home fails to meet the standards, AACQA may put the home on a timetable for improvement (TFI), which sets out the required improvements and the maximum time allowed for addressing those expected outcomes that were not met. By the end of the timetable, the AACQA will arrange for assessors to conduct a review audit. If the standards are still not met, the home's accreditation will be varied or revoked. The Department of Health may also decide to impose sanctions on the home. Therefore, meeting aged care accreditation standards is the basic safety requirement imposed by the Australian government on a RAC home in aged care service provision.

There are four RAC accreditation standards in Australia: 1- Management systems, staffing and organizational development; 2- Health and personal care; 3- Care recipient lifestyle; and 4Physical environment and safe systems [18]. Each standard includes a series of expected outcomes. There are 44 of these outcomes across the four standards with which an RAC home must comply at all times in order to meet accreditation requirements [19]. Common to all four standards are the outcomes of continuous improvement, regulatory compliance, education and staff development. The Principle of Standard One is to be responsive to the needs of residents, their representatives, 
staff and stakeholders, and the changing environment in which the service operates. The six outcomes that are specific to Standard One are comments and complaints, planning and leadership, human resource management, inventory and equipment, information systems and external services. The requirement for outcome 1.8, information systems, which was a focus for this study, is that 'Effective information management systems are in place'.

The publicly available RAC accreditation reports provide the most objective and authoritative information on whether an RAC home meet the accreditation outcome of 1.8 information systems The reports also contain information about the type of records used in an RAC home, being EHR or a paper records-based system. By analyzing the information in Section 1.8 of the accreditation reports, it is possible to infer which indicators of 'effective information management systems' were used by the accreditation agency and whether these had differed between RAC homes that used EHR and those that had paper-based records. Therefore, our approach to address the research question was to conduct a comprehensive analysis of Australian aged care accreditation reports.

\section{METHODS}

We followed a four-step process to extract and analyze data from these reports: data sourcing and processing, data cleaning, data restructuring and labelling, and analysis.

\section{Data sourcing and processing}

Data were sourced from the web site of the Aged Care Standards and Accreditation Agency in December 2013. We downloaded 2,754 aged care accreditation reports that were produced from 
We converted the original reports in PDF format to computer-program readable text formats (e.g. .txt files) using software Adobe Acrobat Pro. We extracted the relevant sections in all reports, including 44 expected accreditation outcomes (Figure 1a) and Outcome 1.8 Information Systems (Figure 2a) into text files (Figures $1 \mathrm{~b}$ and $2 \mathrm{~b}$ ).

\begin{tabular}{|c|c|}
\hline \multicolumn{2}{|c|}{ Most recent decision concerning performance against the Accreditation Standards } \\
\hline \multicolumn{2}{|c|}{$\begin{array}{l}\text { Standard 1: Management systems, staffing and organisational development } \\
\text { Principle: } \\
\text { Within the philosophy and level of care offered in the residential care service, management } \\
\text { systems are responsive to the needs of residents, their representatives, staff and } \\
\text { stakeholders, and the changing environment in which the service operates. }\end{array}$} \\
\hline Expected outcome & $\begin{array}{c}\text { Accreditation Agency } \\
\text { decision }\end{array}$ \\
\hline 1.1 Continuous improvement & Met \\
\hline 1.2 Regulatory compliance & Met \\
\hline 1.3 Education and staff development & Met \\
\hline 1.4 Comments and complaints & Met \\
\hline 1.5 Planning and leadership & Met \\
\hline 1.6 Human resource management & Met \\
\hline 1.7 Inventory and equipment & Met \\
\hline 1.8 Information systems & Not met \\
\hline 1.9 External services & Met \\
\hline
\end{tabular}

Figure 1a- An example of the expected accreditation outcomes for Standard 1 in the original accreditation report in PDF format.

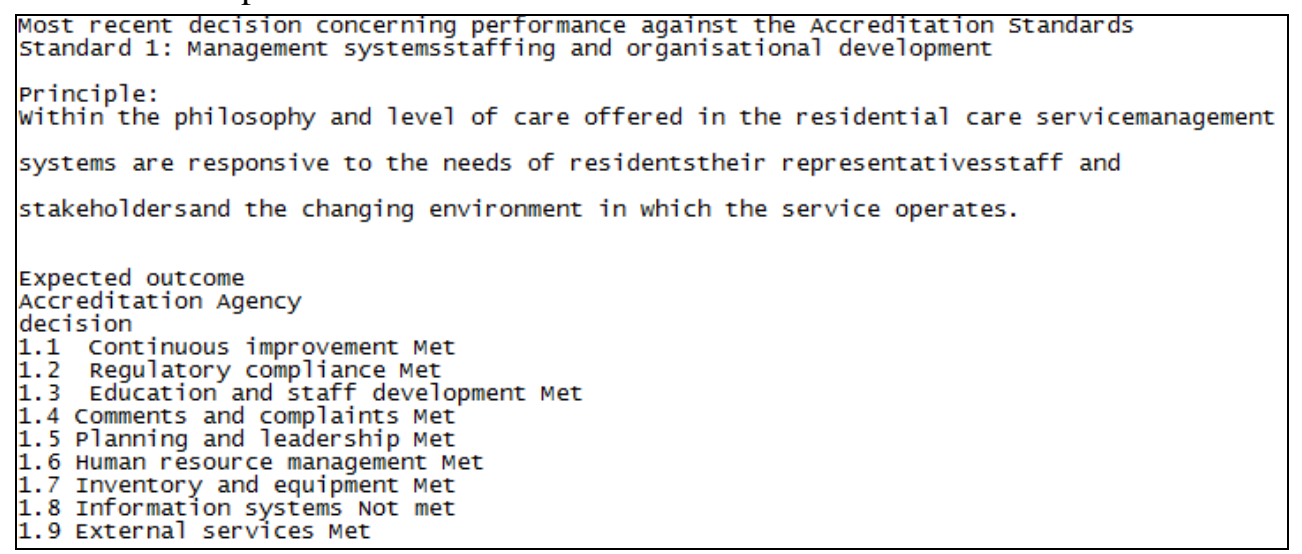

Figure 1b- An example of the processed text format of the content presented in Figure 1a. 


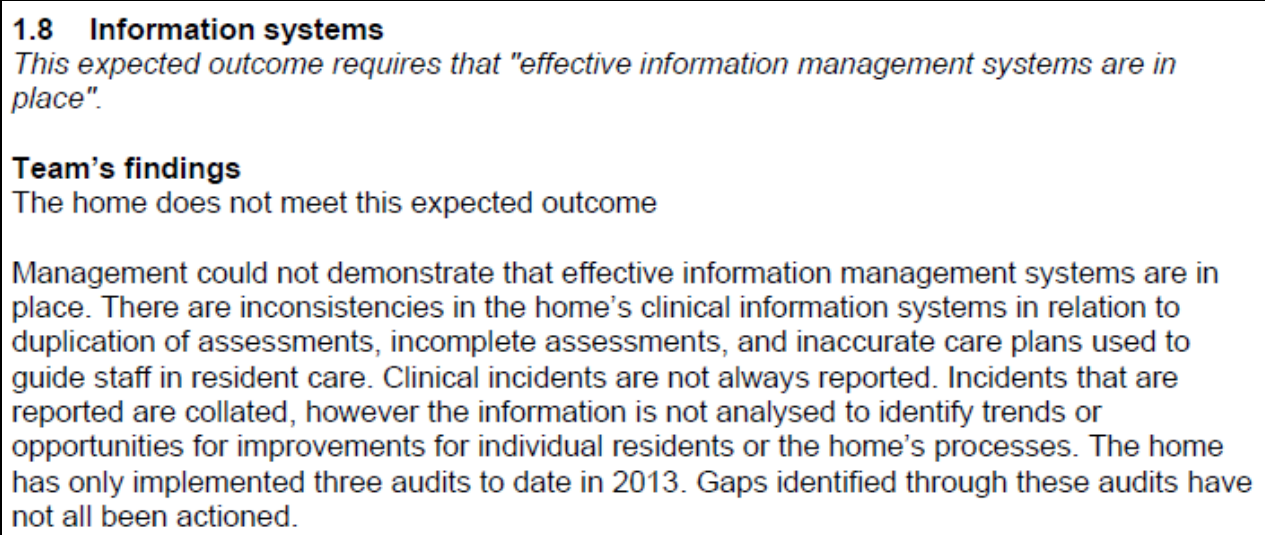

Figure 2a-An example of findings for Outcome 1.8 Information Systems in the original accreditation report in PDF format.

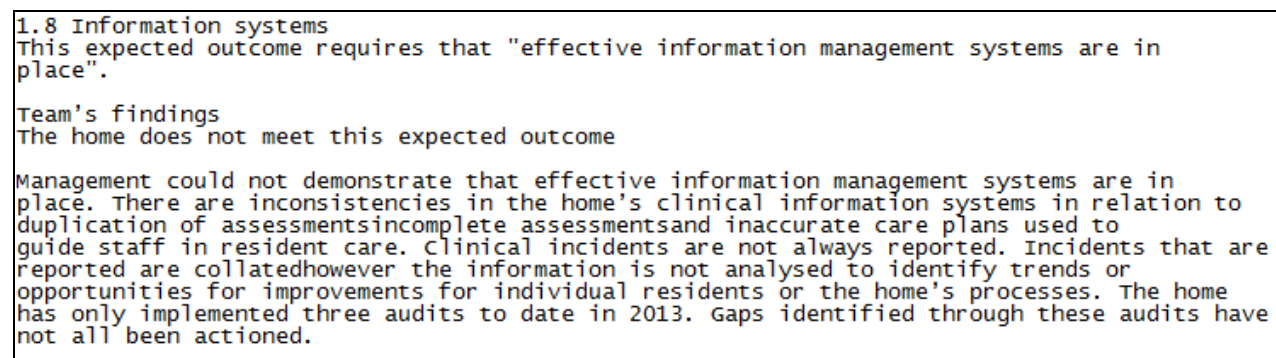

Figure 2b-An example of the processed txt format of the content presented in Figure 2a.

\section{Data cleaning}

The first author manually compared the converted text files with the original PDF documents for 2,754 reports. The incorrect character encoding was concentrated on list characters like '•’ in PDF format. These were converted to '?' or '????' in txt format. Otherwise, the errors did not influence reading the content.

\section{Data restructuring and labelling}

Data were labeled according to two criteria: failing to meet one or more aged care accreditation outcomes, and using some form of EHR. First we identifed the RAC homes that failed to meet one or more aged care accreditation outcomes by searching the content such as that presented in Table $1 \mathrm{~b}$ using the key word 'not met'.

To identify the RAC homes that used an EHR system and those used paper records, first we read through 50 copies of the accreditation reports and found that different terms were used to describe 
an electronic record system. Based on the terms we identified, we developed a list of keywords that was used to identify whether an RAC home used an EHR system or paper records. They included electronic clinical plan, electronic clinical documentation, electronic clinical information, electronic documentation, electronic care plan, electronic care documentation, electronic care information and electronic health record.

We scanned section 1.8 Information Systems in the reports (see Figure 2b), and a list of documents that a RAC home submitted to the accreditation agency for desk audit. Based on this, we used a program to automatically structure the name of an RAC home (from document name), frequnency of matching the keywords and details of matching (e.g. 30 characters before and after each keyword) into an Excel speedsheet (Table 1). The reliability of the labels in Table 1 was further validated by manual checking against the original documents.

Table 1. An example of the list of RAC homes that matched keywords 'electronic care plan'

\begin{tabular}{|l|l|l|}
\hline Homes & $\begin{array}{l}\text { Matching } \\
\text { times }\end{array}$ & Details of matching \\
\hline Spring Valley & 1 & $\begin{array}{l}\text {..uality improvement plan 2012 Contractor database } \\
\text { Electronic care planning, assessment and documentation } \\
\text { program Emergen... }\end{array}$ \\
\hline Sunset Village & 2 & $\begin{array}{l}\text {..tion calendar, attendance and evaluation records Electronic } \\
\text { care planning system Emergency evacuation plans and... } \\
\ldots \text { evaluation, care plans are now completed on the } \\
\text { electronic care planning system. Clinical staff are satisfied } \\
\text { the ... }\end{array}$ \\
\hline Smith House & 0 & \\
\hline
\end{tabular}

Afterwards, we aggregated all RAC homes into four groups: Group 1 - meeting all accreditation standards and using EHR, Group 2 - meeting all accreditation standards and using paper records, Group 3 - not meeting one or more accreditation standards and using EHR, and Group 4 - not meeting one or more accreditation standards and using paper records. 


\section{Data analysis}

Both quatitative and qualitative data analyses were conducted in this study. Pearson's Chi-square test was used to identify differences between the four groups of the RAC homes - those that used EHR systems or used paper records in meeting or not meeting aged care accreditation standards. The level of significance was set at $\mathrm{p}=0.05$.

Qualitative content analysis was conducted to identify and classify the indicators for not meeting accreditation Outcome 1.8 Information Systems. This enabled us to identify the statements that described the reasons for failing to meet this outcome. We compared these statements with the contributions of EHR to residential aged care suggested by the previous studies.

\section{RESULTS}

Thirteen RAC homes were found to not meet one or more accreditation standards. These RAC homes and the relevant accreditation outcomes that at least one RAC home did not meet are listed in Table 2.

Table 2. The accreditation outcomes that at least one of 13 RAC homes did not meet ( F: not meet an expected accreditation outcome).

\begin{tabular}{|c|c|c|c|c|c|c|c|c|c|c|c|c|c|c|c|c|c|c|c|c|c|c|c|c|c|}
\hline \multirow{2}{*}{$\begin{array}{l}\text { RAC } \\
\text { Home }\end{array}$} & \multicolumn{25}{|c|}{ Expected Accreditation Outcomes } \\
\hline & & 1.2 & 1.31 & & 1.6 & 1.8 & 2.1 & 2.3 & 2.4 & 2.5 & 2.6 & 2.7 & 2.8 & 2.10 & 2.11 & 2.12 & 2.13 & 2.14 & 2.16 & \begin{tabular}{l|l}
3.1 & 3 \\
\end{tabular} & \begin{tabular}{l|l|l}
3.2 & 3.4 \\
\end{tabular} & \begin{tabular}{|l|l|l|l|l|}
4 & 3.6 & 4.1 \\
\end{tabular} & 4.44 .5 & \begin{tabular}{|l|l|l|}
4.6 & 4 \\
\end{tabular} & $\begin{array}{lll}4.7 & 4.8 \\
\end{array}$ \\
\hline 1 & & & & 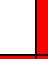 & $\mathrm{F}$ & & & & & & & & & & & & & & & & & & & & \\
\hline 2 & & & & $F$ & $F$ & $F$ & & & & & & $\mathrm{~F}$ & $\mathrm{~F}$ & $\mathrm{~F}$ & $\mathrm{~F}$ & & & & & & & & & & \\
\hline 3 & & & & $F$ & $F$ & $F$ & & & & & & $F$ & $\mathrm{~F}$ & $\mathrm{~F}$ & & & & & & & & & & & \\
\hline 4 & & & & & & & $\mathrm{~F}$ & $\mathrm{~F}$ & & & & & & & & & $\mathrm{~F}$ & & & & & $\mathrm{~F}$ & & & \\
\hline 5 & & & & & & 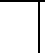 & & & & & & & & & & & $\mathrm{F}$ & & & & $\mathrm{F}$ & & & & \\
\hline 6 & & & & & & $\mathrm{~F}$ & & & & & & & $\Gamma$ & & & $\mathrm{F}$ & $\mathrm{F}$ & & & & & & & & \\
\hline 7 & & & & & & $\mathrm{~F}$ & & $\mathrm{~F}$ & $\mathrm{~F}$ & & & & & & & & 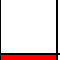 & & $\mathrm{F}$ & & & & & & \\
\hline 8 & & & & & & $F$ & & & 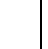 & & & & & & & & $\mathrm{F}$ & & & & & & $\mathrm{F}$ & & \\
\hline 9 & & & & & & & & & $\mathrm{~F}$ & & & & & & & & $\mathrm{~F}$ & & & & & & & & \\
\hline 10 & & & 1 & & $\mathrm{~F}$ & $\mathrm{~F}$ & $\mathrm{~F}$ & $\mathrm{~F}$ & $\mathrm{~F}$ & & $\mathrm{~F}$ & $F$ & $\mathrm{~F}$ & & & & & $\mathrm{~F}$ & & $\mathrm{~F}$ & & & & & \\
\hline 11 & & & $\mathrm{~F}$ & & $\mathrm{~F}$ & $\mathrm{~F}$ & $\mathrm{~F}$ & $\mathrm{~F}$ & $\mathrm{~F}$ & $\mathrm{~F}$ & F & F & & & & & & & & & & $\mathrm{F}$ & & & \\
\hline 12 & & & & & $\mathrm{~F}$ & F & & & $\mathrm{F}$ & & & $F$ & & $F$ & F & & $\mathrm{F}$ & & & & & & & & \\
\hline
\end{tabular}


Difference in meeting accreditation standards between RAC homes using EHR and those using paper records

Of the 2,754 RAC homes audited, 1,031 (37.4\%) used an EHR system for client health and personal care information management and 1,723 (62.6\%) used only paper records. Only 13 homes $(0.5 \%)$ failed to meet one or more of the 44 accreditation outcomes. One of these homes used an EHR system and met requirements for Outcome 1.8. Of the twelve homes that used paper records, nine failed in Outcome 1.8 (see Figure 3).

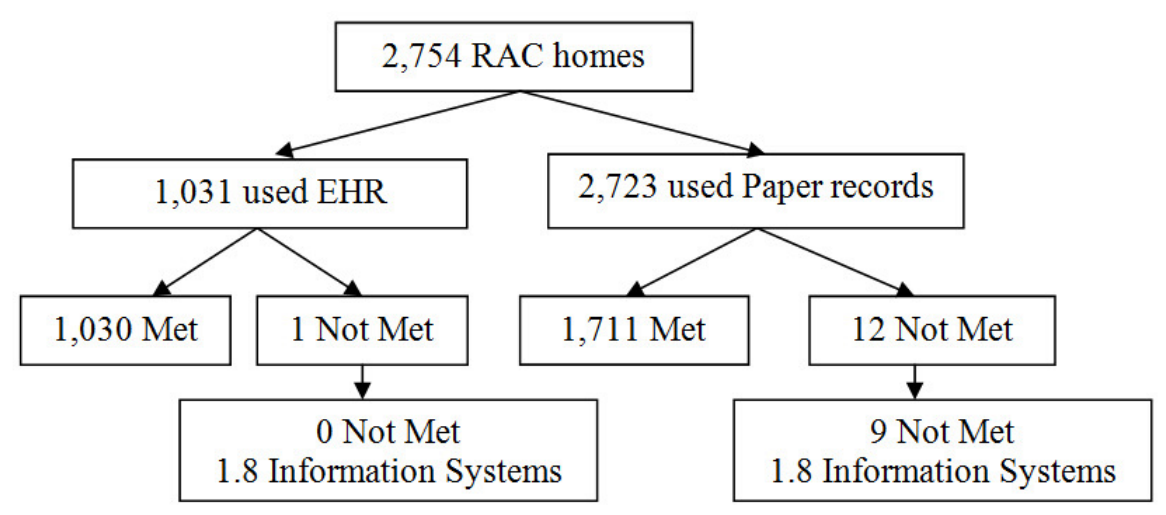

Figure 3. An outline of the RAC homes that used EHR or paper records, met or did not meet the accreditation outcomes, and whether they met or did not meet the accreditation Outcome 1.8 Information Systems

The result of the Chi square test suggested that the proportion of RAC homes using EHR that met accreditation standards (99.9\%) was significantly higher than that of their counterparts using paper records $(99.3 \%, \mathrm{p}=0.026)$

\section{Risk indicators for failure to meet Outcome 1.8 Information Systems}

Six risk indicators were identified in the reports for the nine RAC homes using paper records that failed to meet the information system outcome (Table 3). Staff in six homes did not have access to accurate and appropriate information (R1). Monitoring mechanisms were not effective in identifying deficiencies in information systems in four homes (R2). Two homes did not always 
report clinical incidents (R3). There were insufficient records of residents' clinical changes in two homes (R4). One home failed to produce accurate care plans (R5) and one home's communication processes were not effective (R6). These deficiencies led the agency to conclude that these RAC homes did not have effective information systems.

Table 3-Risk indicators in reports for RAC homes using paper records that failed the information system outcome.

\begin{tabular}{lcccccc}
\hline Homes & R1 & R2 & R3 & R4 & R5 & R6 \\
\hline H1 & F & & & F & & \\
H2 & F & & & F & & \\
H3 & F & & F & & F & \\
H4 & & F & & & & F \\
H5 & F & F & F & & & \\
H6 & & & & & & \\
H7 & F & F & & & & \\
H8 & & F & & & & \\
H9 & F & & & & & \\
\hline Total & 6 & 4 & 2 & 2 & 1 & 1 \\
\hline
\end{tabular}

$\mathrm{F}=$ Fail information system accreditation outcome. R1: No access to accurate and appropriate information. R2: Monitoring mechanisms were not effective in identifying deficiencies in information systems. R3: Not reporting clinical incidents. R4: Insufficient recording of residents' clinical changes. R5: Not providing accurate care plans. R6: Communication processes were not effective.

\section{DISCUSSION}

This study aimed at identifying the contribution of EHR to managing risks for information system accreditation in RAC homes. We found that EHR systems had already been adopted by $37.4 \%$ of 2754 RAC homes. Thirteen RAC homes did not meet all expected outcomes in the Australian standards. Of these, nine out of 12 that used paper-based records failed the outcome for information systems. Through analysis of the records for these nine homes, we identified six risk indicators in information systems, which were used by the accreditation agency to decide that the 
information system accreditation outcome had not been met. This provided insight about the areas of information system management to which RAC homes may need to pay attention and continuously improve.

The study findings indicate that the overall contribution of EHR to meeting aged care accreditation standards in Australia was very small. Only 9 (0.3\%) RAC homes failed the information system outcome. This may cause stagnation in the adoption of EHR by the rest $62.6 \%$ of RAC homes that were still using paper records by the end of 2013. The further adoption of EHR in Austarlian RAC sector needs to be continuously followed. However, none of the RAC homes that used EHR for information management failed to meet that outcome. Also, the proportion of RAC homes using EHR that met all accreditation standards was significantly higher than that of homes with paper records.

The aged care accreditation system in Australia is established to ensure an RAC service meets the minimum safety standard mandated by the Aged Care Act. It is not a quality ranking system, such as a star ranking system for e-Bay, which is available to the general public, thus providing the pressure and incentive for the aged care service providers to improve services. This explains why only $0.3 \%$ of RAC homes in this study failed the standard. Therefore, there is a lack of policy incentive for RAC homes in Australia to further improve quality once the minimum safety standard audited by the aged care accreditation system is met. This may cause inertia in the whole sector and stagnation in innovation, which needs to be further confirmed and studied.

Nevertheless the strength of this study is that it had the advantage of a nationwide overview of the performance of Australian RAC homes in information management and the possible contribution of EHR to this process. We believe it provides some indication of the benefits from EHR in RAC, 
consistent with those found in previous studies using other methods $[21,20,7,8,22]$.

An inevitable limitation is that what we have reported is an association between EHR and accreditation, rather than decisive evidence that use of EHR is a reason for RAC homes to perform better in accreditation. Also, the sample size for detailed analysis of risk factors for failing to meet accreditation standards is small. Another limitation of the study is it does not provide information on practice details of the sort obtained from observational studies with small numbers of homes.

\section{CONCLUSION}

This study identified six risk indicators for an RAC home to fail the information system accreditation standard in Australia. While a small number of RAC homes that used paper records failed accreditation standard on information systems, those that used EHR fully complied.

\section{KEY POINTS:}

- A small number of RAC homes that used paper records failed accreditation standard on information systems.

- Six risk indicators for an RAC home to fail the information systems outcome were identified.

\section{REFERENCES}

1. Institute of Medicine (2000) Improving the Quality of Long-Term Care. http://iom.nationalacademies.org/Reports/2000/Improving-the-Quality-of-Long-Term-Care.aspx. Accessed 2 December 2015

2. Institute of Medicine (2003) Priority Areas for National Action: Transforming Health Care Quality. http://iom.nationalacademies.org/Reports/2003/Priority-Areas-for-National-Action-Transforming-Healt h-Care-Quality.aspx. Accessed 2 Dec 2015

3. Institute of Medicine (2004) 1st Annual Crossing the Quality Chasm Summit: A Focus on Communities.http://iom.nationalacademies.org/Reports/2004/1st-Annual-Crossing-the-Quality-ChasmSummit-A-Focus-on-Communities.aspx. Accessed 2 Dec 2015 
4. Resnick, H.E., Manard, B.B., Stone, R.I., and Alwan, M (2009), Use of electronic information systems in nursing homes: United States. Journal of the American Medical Informatics Association. 16(2):179-186. 8p.

5. P, Y., (2012) Aged care IT in Australia-the past, present and future. Electronic Journal of Health Informatics. 7(2):e2.

6. Munyisia EN, Yu P, Hailey D (2011) Does the introduction of an electronic nursing documentation system in a nursing home reduce time on documentation for the nursing staff? International journal of medical informatics 80 (11):782.

7. Wang N, Yu P, Hailey D (2013) Description and comparison of quality of electronic versus paper-based resident admission forms in Australian aged care facilities. International journal of medical informatics 82:313-324.

8. Wang N, Yu P, Hailey D (2015) The quality of paper-based versus electronic nursing care plan in Australian aged care homes: A documentation audit study. International journal of medical informatics $84: 561-569$.

9. Wang, N., Yu, P., Hailey, D. and Oxlade, D., Developing measurements of the quality of electronic versus paper-based nursing documentation in Australian aged care homes. Electronic Journal of Health Informatics, 6(1):1-6,2011.

10. Abramson EL, McGinnis S, Moore J, Kaushal R (2014) A statewide assessment of electronic health record adoption and health information exchange among nursing homes. Health Services Research 49 (1 Pt 2):361-372.

11. Ben-Assuli O, Shabtai I, Leshno M, Hill S (2014) EHR in Emergency Rooms: Exploring the Effect of Key Information Components on Main Complaints. Journal of medical systems 38 (4):1

12. Ben-Assuli O, Ziv A, Sagi D, Ironi A, Leshno M (2016) Cost-Effectiveness Evaluation of EHR: Simulation of an Abdominal Aortic Aneurysm in the Emergency Department. Journal of medical systems 40 (6):141-141.

13. Yu P, Zhang Y, Gong Y, Zhang J.(2013) Unintended adverse consequences of introducing electronic health records in residential aged care homes. International Journal of Medical Informatics, 82(9):772-88

14. Clancy L, Happell B, Moxham L (2008) Assessing risk in aged care mental health. Australian nursing journal (July 1993) 15 (7):30

15. De Bellis A (2010) Australian Residential Aged Care and the Quality of Nursing Care Provision. Contemporary Nurse: A Journal for the Australian Nursing Profession 35 (1):100-113

16. Australian Aged Care Quality Agency (2014) Assessor handbook Australian Aged Care Quality Agency.https://www.aacqa.gov.au/for-providers/residential-aged-care/resources/other-resources/Assess orhandbook.pdf. Accessed Jun 12016

17. Australian Government (1997) Aged Care Act 1997. Federal Register of Legislation. https://www.legislation.gov.au/Series/C2004A05206. Accessed Jun 12016

18. ComLaw AG (2014) Quality of care principles 2014.

19. Australian Aged Care Quality Agency (2014) Accreditation standards.

20. Munyisia EN, Yu P, Hailey D (2011) The changes in caregivers' perceptions about the quality of information and benefits of nursing documentation associated with the introduction of an electronic documentation system in a nursing home. International journal of medical informatics 80:116-126.

21. Lin IC, Chien Y-M, Chang IC (2006) Quality evaluation on an e-learning system in continuing professional education of nurses. Studies In Health Technology And Informatics 122:220-224 
22. Zhang YT, Yu P, Sen J (2011) Evaluating the Benefits of Introducing Electronic Nursing Documentation Systems in Residential Aged Care Facilities. Abstract. Paper presented at the Health Informatics Conference 2011, Brisbane, Australia, 